\title{
An approach to give grade for each departments of a university based on their performances
}

\section{Raissi, Sadigh [1]}

Nojavan, Majid

\author{
Assistant Professors
}

Industrial Engineering Department

\section{Islamic Azad University, Tehran South Branch, Tehran, Iran}

\section{Abstract}

Decide on the most efficient department could help university managers to conduct their decision in proper manner especially in their resource allocation programs, encouraging decision support systems, quality metrics and so on. Different decision maker may use different information bases, unlike relative weights to their criteria and also different uncertainty levels in their expressions. They could utilize many quantitative or qualitative methods based on their knowledge and experiences. There is no unique and commonly accepted procedure to accomplish such decision properly. This paper tends to advise a systematic approach to handle such management problems. Through this paper readers will be familiar with a simple theory and easy of use method called Analytic Hierarchy Process (AHP), the way to compare different departments in a given university based on their commonly experts expression and a sample hierarchy structure for the such desired cases. This method called Fuzzy AHP and abbreviated FAHP later. In order of more warning to the prescribed efficient method we avoided to deliver detail arithmetical calculations. 
Keywords: Multiple-attribute decision-making (MADM), Fuzzy analytic hierarchy process (FAHP), Efficient department selection method, Quality of education.

\section{Introduction}

The analytic hierarchy process (AHP) was first introduced by Saaty in 1971 to solve the scarce resources allocation and planning needs for the military [11]]. Since its introduction, the AHP has become one of the most widely used multiple-attribute decision-making (MADM) methods, and has been used to solve unstructured problems in different areas of human needs and interests, such as industrial, economic and management sciences [[2]]. The procedures of the AHP involve six important steps [3]].

1. Define the unstructured problem and state clearly the objectives and outcomes.

2. Decompose the complex problem into a hierarchical structure with decision elements (decision makers, criteria, detailed criteria and alternatives).

3. Utilize pair wise comparisons among decision elements and form comparison matrices.

4. Apply the eigenvalue method to estimate the relative weights of the decision elements.

5. Confirm the consistency property of matrices to ensure that the judgments of decision makers are consistent.

6. Aggregate the relative weights of decision elements to obtain an overall rating for the alternatives.

Conventional AHP that requires the selection of arbitrary values in pair wise comparison may not be sufficient and uncertainty should be considered in some or all pair wise comparison values [4],,5]].

Zadeh in 1965 introduced fuzzy set theory to solve problems involving the absence of sharply defined criteria [6]]. If uncertainty (fuzziness) of human decision- making is not taken into account, the results can be misleading. A commonality among terms of expression, such as "very likely", "probably so", "not very clear", "rather dangerous" that are often heard in daily life, is that they all contain some degree of uncertainty [[7], [8]]. Fuzzy theory thus is used to solve such kind of problems, and it has been applied in a variety of fields in the last four decades.

Theory of fuzzy sets has evolved in various directions, and two distinct directions are: treating fuzzy sets as precisely defined mathematical objects subject to the rules of classical logic, and the linguistic approach. The 
underlying logic of linguistic approach is that the truth-values are fuzzy sets and the rules of inference are approximate rather than exact [[9]]. Since the fuzzy linguistic approach can take the optimism/pessimism rating attitude of decision makers into account, linguistic values, whose membership functions are usually characterized by triangular fuzzy numbers, are recommended to assess preference ratings instead of conventional numerical equivalence method [101]. As a result, the fuzzy AHP should be more appropriate and effective than conventional AHP in real practice where an uncertain pair wise comparison environment exists.

\section{Fuzzy analytic hierarchy process (FAHP)}

FAHP could be used to generate the weighting of the different alternatives and their performance indicators. To apply this method, there are six essential steps [3]:

a) Erect the hierarchical structure with decision elements (e.g., decision makers, criteria, sub criteria and alternatives). Each decision maker is asked to express relative importance of two decision elements in the same level (e.g. two criteria) by a nine-point scale. Collect the scores of pair wise comparison, and form pair wise comparison matrices for each of the $\mathrm{K}$ decision makers.

b) Analyze consistency. The priority of the elements can be compared by the computation of eigenvalues and eigenvectors. The consistency property of the matrix is then checked to ensure the consistency of judgments in the pair wise comparison. The consistency index $(\mathrm{Cl})$ and consistency ratio (CR) are defined by Leung and Cao [111]. As suggested by Saaty [112], the upper threshold CR values are 0.05 for a $3 \times 3$ matrix, 0.08 for a $4 \times 4$ matrix, and 0.10 for larger matrices. If the consistency test is not passed, the original values in the pair wise comparison matrix must be revised by the decision maker.

c) Construct fuzzy positive matrices. The scores of pair wise comparisons are transformed into linguistic variables, which are represented by positive fuzzy numbers such as triangular fuzzy numbers [113]] listed in Table 1.

Table 1: Linguistic terms and their equivalents on triangular fuzzy numbers

\begin{tabular}{|c|c|c|}
\hline Linguistic variables & $\begin{array}{c}\text { Positive triangular } \\
\text { fuzzy numbers }\end{array}$ & $\begin{array}{c}\text { Positive reciprocal } \\
\text { triangular fuzzy } \\
\text { numbers }\end{array}$ \\
\hline Extremely strong & $(9,9,9)$ & \\
\hline Intermediate & $(7,8,9)$ & \\
\hline
\end{tabular}




\begin{tabular}{|c|l|l|}
\hline Very strong & $(6,7,8)$ & \\
\hline Intermediate & $(5,6,7)$ & \\
\hline Strong & $(4,5,6)$ & \\
\hline Intermediate & $(3,4,5)$ & \\
\hline Moderately strong & $(2,3,4)$ & \\
\hline Intermediate & $(1,2,3)$ & \\
\hline Equally strong & $(1,1,1)$ & $(1,1,1)$ \\
\hline
\end{tabular}

d) Calculate fuzzy weights. Buckley [14]] and later Csutora and Buckley [[15]] proposed a method called Lambda-Max to calculate the fuzzy weights of decision elements.

e) Integrate the opinions of different decision makers by using the geometric average method to combine the fuzzy weights of decision makers.

f) Obtain final ranking. Based on the equation proposed by Chen [16] , a closeness coefficient is defined to obtain the ranking order of each alternative with respect to criterion structure and finally select the best alternative.

\section{Construction of hierarchical structure to give grade of departments}

The first step is to construct a hierarchical structure for efficient department selection problem. The goal is to select the best department within a given faculty of university. For example suppose there are two decision makers that are involved in the selection process, i.e. DM1 and DM2, and five criteria for the selection, i.e.:

1- Research project contracts (RPC)

2- On hand possibilities (OHP) such as number of researchers, number of research laboratory, amount of computers and software and so on.

3- Totally graduated students (GS)

4- Knowledge procreation (KP) in the form of published papers and books, creation and explorations, patents, organized scientific conferences, ...

5- Quality of trainings (QOT) 
There are six departments to be considered which called A, B, C, D, E and $F$. The methods would be analyzed with respect to the criteria in the third level of the hierarchy, as shown in Figure 1.

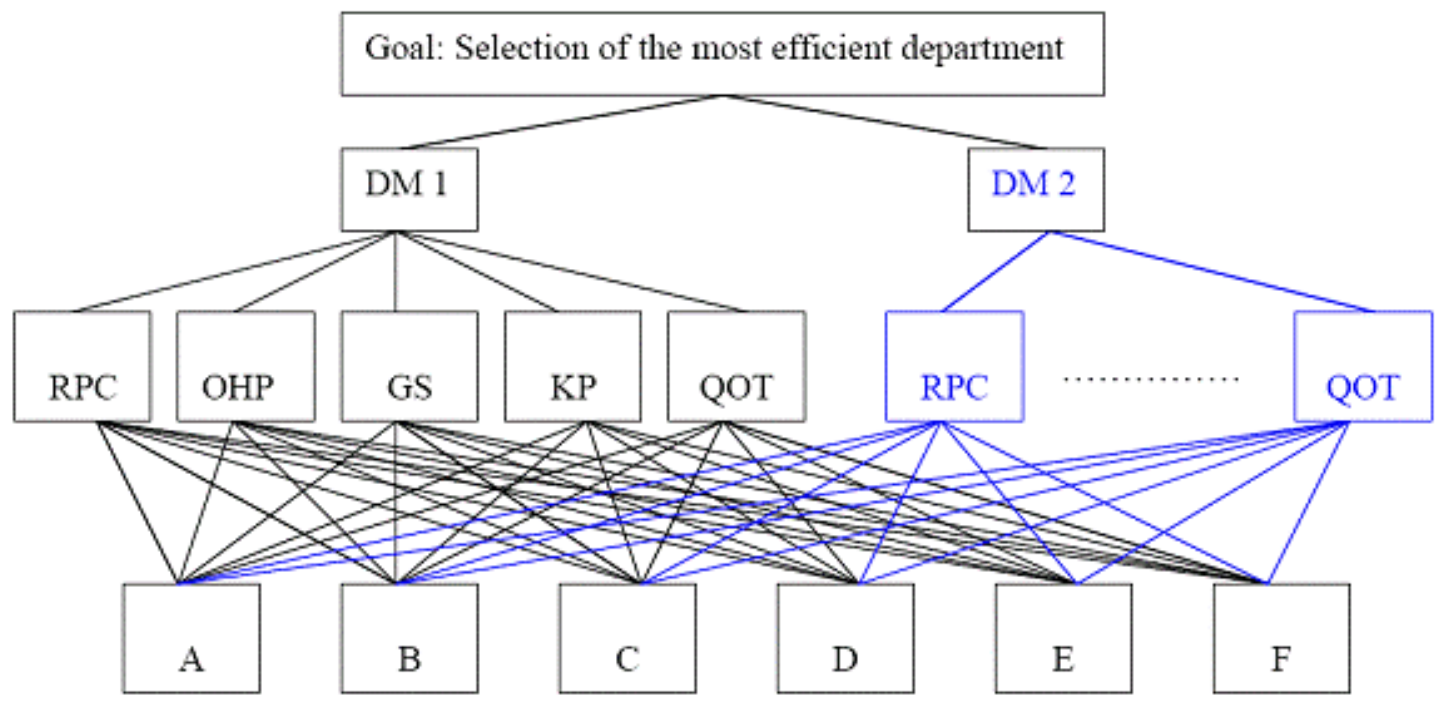

Figure 1: The most efficient educational department selection hierarchy

\section{Conclusion}

One of the commonly real problems of higher educational system is to properly compare of different educational departments. They work both in educational and research activities. Analyzing their performances needs to focus on different criteria such as the amount and size of research contracts, on hand possibilities, number of graduated students in bachelor, master and doctorate degree, Knowledge procreation, quality of trainings and so on.

To give grade for each department on a given university is a complicated problem and need to apply modern decisions making techniques which could explain the proper efficiency level for a higher educational system. It is the determinant for the throughput of an effective educational system. Generally, existing literature invariably overcome such problem using one dimensional analysis. The present study proposes a fuzzy MADM methods-AHP and fuzzy-based method, in modeling such decision. This method use a hierarchy structure such as mentioned by a sample and utilize the ordinary experts expressions to determine relative pair wise weights. The AHP uses deterministic performance ratings and attribute weights, whilst the fuzzy- 
based method uses linguistic metrics. Both methods, whilst concluding the same design alternative for the case study problem, differ from the existing literature. The main aim of the present paper was to warn with such recommended approach. The detailed calculation could easily be set up by familiarized experts through tracing the cited references.

\section{References}

[1] - Corresponding author, Raissi@azad.ac.ir.

[1]- Saaty, T. L. (1980). The analytic hierarchy process. New York: McGraw-Hill.

[2]- Chen S.J. and Hwang, C.L. (1992). Fuzzy Multiple Attribute Decision Making: Methods and Applications, Lecture Notes in Economics and Mathematical Systems, Springer Verlage, Berlin.

[3]- Amy H.I. Lee et al. (2006). A fuzzy AHP and BSC approach for evaluating performance of IT department in the manufacturing industry in Taiwan, Expert Systems with Applications, article on press.

[4]- Basak, I. and Saaty, T.L. (1993), Group decision making using the analytic hierarchy process, Mathematical and Computer Modeling, 17, 233-247.

[5]- Basak, I. (1997). Rank-based statistical procedures in analytic hierarchy process, European Journal of Operational Research, 101, 39-50.

[6]- Zadeh, L. A. (1965). Fuzzy sets. Information and Control, 8, 338-353.

[7]- Tsaur, S. H., Tzeng, G. H., \& Wang, K. C. (1997). Evaluating tourist risks from fuzzy perspectives. Annals of Tourism Research, 24(4), 796-812.

[8]- Tsaur, S. H., Chang, T. Y., \& Yen, C. H. (2002). The evaluation of airline service quality by fuzzy MCDM. Tourism Management, 23, 107-115.

[9]- Gupta, M. M., Saridis, G. N., \& Gaines, B. R. (1977). Fuzzy automata and decision processes. New York: Elsevier North-Holland.

[10]- Liang, G. S., \& Wang, M. J. (1994). Personnel selection using fuzzy MCDM algorithm. European Journal of Operational Research, 78, 22-33.

[11]- Leung, L.C. and Cao, D. (2000). On consistency and ranking of alternatives in fuzzy AHP, European Journal of Operation Research, Vol. 124.

[12]- Saaty, T. L. (1994). How to make a decision: the analytic hierarchy process. Interfaces, 24(6), 19-43.

[13]- Van Laarhoven, P. J. M. and Pedrycs, W. (1993). A Fuzzy extension of Saaty's priority theory, Fuzzy Sets and Systems, Vol. 11.

[14]- Buckley, J.J. (1985). Fuzzy hierarchical analysis, Fuzzy Sets and Systems, Vol. 17.

[15]- Csutora, R., \& Buckley, J. J. (2001). Fuzzy hierarchical analysis: the Lambda-Max method. Fuzzy Sets and Systems, 120, 181-195. 
[16]- Chen, C. T. (2000). Extensions of TOPSIS for group decision-making under fuzzy environment, Fuzzy Sets and Systems, 114, 1-9. 